\title{
Use of electrochemical sensors for measurement of air pollution: correcting interference response and validating measurements
}

\author{
Eben S. Cross ${ }^{1}$, Leah R. Williams ${ }^{1}$, David K. Lewis ${ }^{1,2}$, Gregory R. Magoon ${ }^{1}$, Timothy B. Onasch ${ }^{1}$, \\ Michael L. Kaminsky ${ }^{3}$, Douglas R. Worsnop ${ }^{1}$, and John T. Jayne ${ }^{1}$ \\ ${ }^{1}$ Center for Aerosol and Cloud Chemistry, Aerodyne Research, Inc., Billerica, MA 01821, USA \\ ${ }^{2}$ Department of Chemistry, Connecticut College, New London, CT 06320, USA \\ ${ }^{3}$ Massachusetts Institute of Technology, Cambridge, MA 02139, USA \\ Correspondence to: Eben S. Cross (escross@aerodyne.com)
}

Received: 28 April 2017 - Discussion started: 5 May 2017

Revised: 22 August 2017 - Accepted: 1 September 2017 - Published: 29 September 2017

\begin{abstract}
The environments in which we live, work, and play are subject to enormous variability in air pollutant concentrations. To adequately characterize air quality (AQ), measurements must be fast (real time), scalable, and reliable (with known accuracy, precision, and stability over time). Lower-cost air-quality-sensor technologies offer new opportunities for fast and distributed measurements, but a persistent characterization gap remains when it comes to evaluating sensor performance under realistic environmental sampling conditions. This limits our ability to inform the public about pollution sources and inspire policy makers to address environmental justice issues related to air quality. In this paper, initial results obtained with a recently developed lower-cost air-quality-sensor system are reported. In this project, data were acquired with the ARISense integrated sensor package over a 4.5-month time interval during which the sensor system was co-located with a state-operated (Massachusetts, USA) air quality monitoring station equipped with reference instrumentation measuring the same pollutant species. This paper focuses on validating electrochemical (EC) sensor measurements of $\mathrm{CO}, \mathrm{NO}, \mathrm{NO}_{2}$, and $\mathrm{O}_{3}$ at an urban neighborhood site with pollutant concentration ranges (parts per billion by volume, ppb; $5 \mathrm{~min}$ averages, $\pm 1 \sigma)$ : $[\mathrm{CO}]=231 \pm 116 \mathrm{ppb}$ (spanning 84-1706 ppb), $[\mathrm{NO}]=6.1 \pm 11.5 \mathrm{ppb}$ (spanning 0-209 ppb), $\left[\mathrm{NO}_{2}\right]=11.7 \pm 8.3 \mathrm{ppb}$ (spanning $0-71 \mathrm{ppb}$ ), and $\left[\mathrm{O}_{3}\right]=23.2 \pm 12.5 \mathrm{ppb}$ (spanning 0-99 ppb). Through the use of high-dimensional model representation (HDMR), we show that interference effects derived from the variable ambient gas concentration mix and changing environmen-
\end{abstract}

tal conditions over three seasons (sensor flow-cell temperature $=23.4 \pm 8.5^{\circ} \mathrm{C}$, spanning 4.1 to $45.2^{\circ} \mathrm{C}$; and relative humidity $=50.1 \pm 15.3 \%$, spanning $9.8-79.9 \%$ ) can be effectively modeled for the Alphasense CO-B4, NO-B4, NO2$\mathrm{B} 43 \mathrm{~F}$, and Ox-B421 sensors, yielding (5 min average) root mean square errors (RMSE) of 39.2, 4.52, 4.56, and 9.71 ppb, respectively. Our results substantiate the potential for distributed air pollution measurements that could be enabled with these sensors.

\section{Introduction}

Protecting populations from exposure to poor air quality (AQ) is one of the greatest public health challenges affecting all nations on earth (WHO, 2014). For the past half century, developed countries have made an effort to measure concentrations of major pollutants known to degrade health or damage plants and physical structures. Generally, the focus has been on the most populated areas, with an intent to assess daily, monthly, or annual concentrations on a regional basis. While greater spatial and temporal resolution has been desired, the costs of purchasing and operating instruments sufficiently robust, accurate, and free of interferences to generate reliable data has been prohibitive - an instrument to assess a single pollutant at ambient levels can cost many tens to hundreds of thousands of US dollars.

In this situation it is therefore easy to understand the motivation to develop inexpensive, rapid-response air quality monitoring devices that can be deployed in large num- 
bers around point sources or throughout specific neighborhoods to create the desired high spatial and temporal resolution AQ data grid (Snyder et al., 2013; Kumar et al., 2015; McKercher et al., 2017). Indeed, within the past decade, many researchers, entrepreneurs, and manufacturers have pursued the development, deployment, and evaluation of lower-cost devices that measure air pollution (Mead et al., 2013; Williams et al., 2014b; Masson et al., 2015; Jiao et al., 2016; Lewis et al., 2016; Castell et al., 2017; Hagan et al., 2017; Mueller et al., 2017; Zimmerman et al., 2017).

While electrochemical (EC) sensors have formed the basis for workplace and hazardous leak detection applications for many decades (Stetter and Li, 2008), their transition from workplace to ambient air is accompanied by much lower target concentration ranges over which the sensors must accurately measure the analyte species of interest (Borrego et al., 2016). Coincident with the need to resolve much lower concentrations is the need to fully understand and model the influence of non-analyte interferences resulting from changing temperature $(T)$, relative humidity $(\mathrm{RH})$, pressure $(P)$, or other gas molecules that may compete with the oxidationreduction reactions occurring at the working electrode (WE) of a given EC sensor (Mueller et al., 2017). Unless great care is taken when measuring ambient air pollutants, interferences may result in reported pollutant concentrations that are orders of magnitude greater than the true values. At the core of this quantification challenge is the fact that electrochemical sensors rely on resolving very small changes in current $(\mu \mathrm{A})$ and, in turn, reliably converting that raw sensor signal into a concentration. The path from raw sensor output to concentration requires (1) a mechanical design that provides consistent, empirically validated sampling of the ambient air, (2) low-noise electrical circuitry (potentiostats) to amplify and resolve small changes in current, (3) electronic filters to remove electrical transients (e.g., radiofrequency interference), and (4) a method for converting raw signal to concentration that takes into account calibration and interference data.

In order to calibrate and characterize interferences, laboratory and field-based co-location experiments must be carried out spanning the full range of pollutant concentrations and ambient sampling conditions that may be encountered in an actual stand-alone deployment. Deploying lower-cost AQ-sensor systems in the absence of such calibration significantly undermines the credibility of the data. Indeed, reports have appeared recently raising concerns about the reliability of data produced from inexpensive monitoring devices containing EC sensors (Lewis and Edwards, 2016).

This paper describes results obtained from a newly developed, integrated lower-cost EC-sensor system, ARISense, which has been developed at Aerodyne Research, Inc., for simultaneous, real-time measurement of a wide range of ambient-level atmospheric pollutants and accompanying meteorological metrics. Air quality monitoring systems can be roughly divided into three cost tiers: (1) high-cost and high- accuracy systems costing $\sim$ USD 10 000-100 000 per pollutant species, such as those used at regulatory monitoring stations; (2) lower-cost systems costing USD 1000-10 000 per integrated sensor node, such as ARISense, AQMesh, or the Real-time Affordable Multi-Pollutant (RAMP) package recently developed by Carnegie Mellon University and SenSevere (Zimmerman et al., 2017); and (3) low-cost systems (costing USD 10-100 s per device) designed for the consumer market that typically only measure a single pollutant and generally suffer from poor data quality (EPA, 2017). The goal of second tier systems is to provide data quality approaching tier 1 at a small fraction of the cost. In this paper, we describe the mechanical and electronic design of the ARISense system and demonstrate a field-based calibration technique that combines co-located measurements with a high-dimensional model representation (HDMR) of the interferences. Our results show that lower-cost EC-sensor systems can provide reliable measurements of air pollution under real-world ambient concentrations.

\section{Experimental}

\subsection{ARISense}

The ARISense system used in the present study (version 1.0) measures ambient levels of five gaseous pollutants $\left(\mathrm{CO}, \mathrm{NO}, \mathrm{NO}_{2}, \mathrm{O}_{3}\right.$, and $\left.\mathrm{CO}_{2}\right)$, atmospheric aerosol particles $(0.4-17 \mu \mathrm{m}$ in diameter), and related meteorological and environmental parameters (temperature, pressure, relative humidity, wind speed and direction, solar irradiance, and noise). Mechanical drawings of the ARISense system are shown in Fig. 1. Each system is housed in a NEMA (National Electrical Manufacturers Association) weather-proof enclosure (Polycase, PN: YH-080804; $21.8 \mathrm{~cm} \mathrm{~L} \times 13 \mathrm{~cm} \mathrm{D} \times 21.8 \mathrm{~cm} \mathrm{H}$ ) weighing approximately $2.7 \mathrm{~kg}$ fully integrated. ARISense v1.0 is powered off of 120 $240 \mathrm{~V} \mathrm{AC}$ and designed for stationary fixed-site monitoring.

ARISense v1.0 contained the following EC sensors (purchased from Alphasense Ltd., UK): carbon monoxide (COB4), nitric oxide (NO-B4), nitrogen dioxide (NO2-B43F), and total oxidants (Ox-B421). (More recent versions of ARISense have been upgraded to model Ox-B431.) The integrated system also includes a nondispersive infrared (NDIR) carbon dioxide $\left(\mathrm{CO}_{2}\right)$ sensor (Alphasense pyroelectric IRCA1) and an optical particle counter (OPC) for measurement of particulate matter size distributions (number-count; $\sim 0.4 \leq d_{\mathrm{p}} \leq 17 \mu \mathrm{m}$ over 16 size bins; Alphasense OPC-N2). The following environmental and meteorological measurements are also included: relative humidity and temperature sensor (Sensirion AG, PN: SHT21), barometric pressure and temperature sensor (BOSCH, PN: BMP180), solar intensity sensor (OSRAM Opto Semiconductors, PN: BPW 34), and a microphone for audible noise detection (CUI, Inc., PN: CMC-5044PF-A). An anemometer (Davis Instruments, Van- 


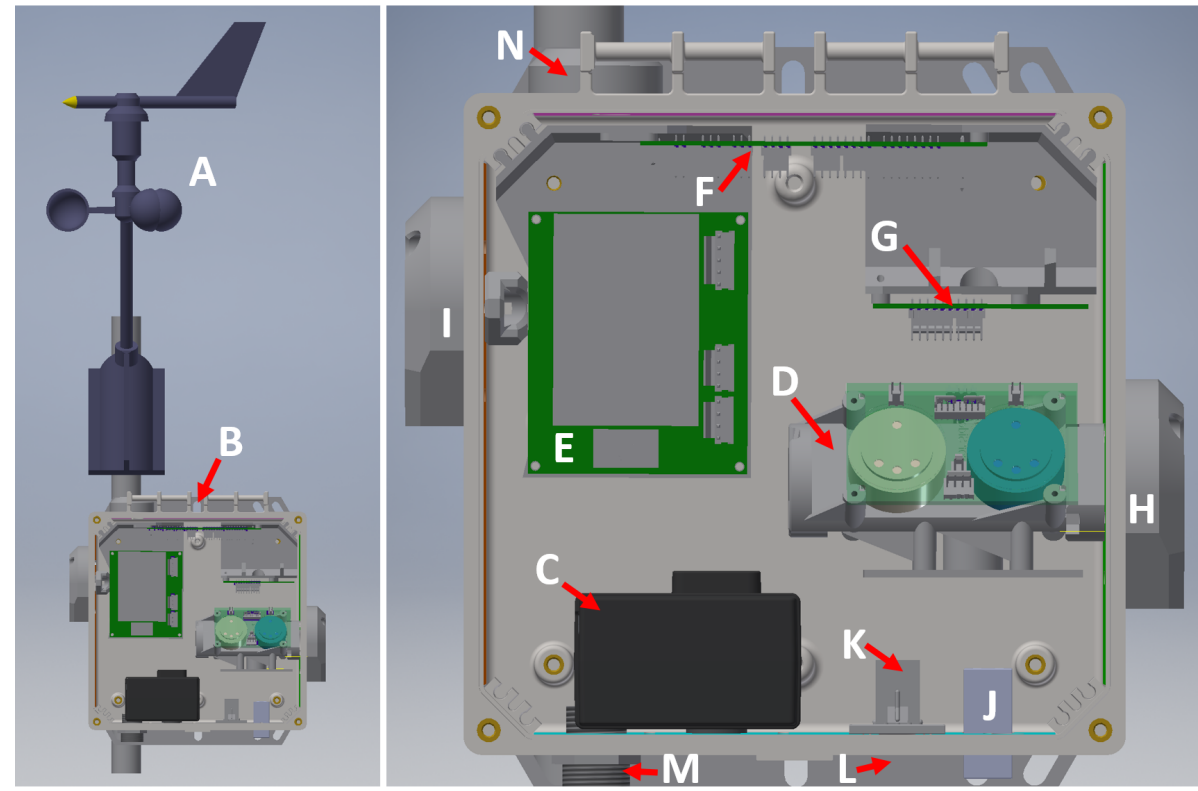

Figure 1. Mechanical drawings (wires excluded) showing the main components of the ARISense system. Each system includes an anemometer (A) mounted to the back bracket of the NEMA enclosure providing a description of the wind fields in the immediate proximity to the gas and particle sampling inlets of the system. Mounting brackets for wall or pole-mount configurations attach at position (B). Expanded view of the internal components reveals the optical particle counter (C), gas sampling manifold (D) with embedded electrochemical and NDIR and RH/T sensors, transformer/power PCB (E), main controller PCB (side view) (F), communication PCB for ethernet connectivity $(\mathrm{G})$, gas sampling inlet and exhaust rain hoods (H, I), RJ11 and RJ45 connections for anemometer data and CAT-5 connectivity (J, K), microphone assembly (L), weather tight AC power input (M), and solar sensor assembly for light intensity measurement (N). The 3-D-printed parts include the gas sampling manifold, rain hoods, exhaust and microphone mounting bracket, solar sensor interface, and PCB mounting scaffold. As described in the text, the gas and particle sampling inlets are separate, with the OPC-N2 sampling through the bottom face of the enclosure to protect from liquid water penetration.

tage Pro 6410) for wind speed and direction was mounted to the top of the ARISense NEMA enclosure, measuring conditions $\sim 60 \mathrm{~cm}$ above the sampling inlets (see Fig. 1).

ARISense electronics were designed to integrate all sensor measurements into a unified data acquisition framework and provide user access and control over the system's configuration and operation. EC-sensor signals were collected and processed by custom-built electronics designed to minimize noise and amplify raw signals (i.e., potentiostat circuitry). Connectivity for v1.0 systems was enabled via hardline CAT-5 ethernet connections (Lantronix XPort Pro). Data were saved at user-defined sampling intervals (5-60 s) onto a local USB drive and (if internet-connected) to the ARISense database (https://arisense.io/), where data are available for real-time visualization and download. Upgraded ARISense systems configured for cellular connectivity and stand-alone solar power are currently under development.

The ARISense system has two sampling inlets, one for measuring gas-phase pollutants and the other dedicated to the measurement of particulate matter. In both cases, the air flow is driven by small DC-powered fans embedded at the downstream end of the sample flow path, minimizing the loss of sticky or reactive gas molecules $\left(\mathrm{NO}_{2}, \mathrm{O}_{3}\right)$ or par- ticles due to surface reactivity or deposition. The gas sample flow includes both an intake and an exhaust port in the NEMA enclosure, protected from water penetration via 3-Dprinted rain hoods (Formlabs; Form 2, stereolithography 3-D printer) mounted to the exterior of the case (see components $\mathrm{H}$ and $\mathrm{I}$ in Fig. 1). The gas sampling flow manifold and internal printed circuit board (PCB) mounting brackets were also 3-D printed. Laboratory tests reveal that the 3-D-printed material is inert to $\mathrm{NO}_{2}$ and $\mathrm{O}_{3}$ and does not result in significant losses of either species when sampling ambient-level concentrations. The gas sampling manifold provides a consistent, compact interface for the four electrochemical sensors as well as the $\mathrm{CO}_{2}$ sensor. The manifold includes an embedded $\mathrm{RH} / T$ sensor positioned adjacent to the electrochemical cells which is used to model the temperature and relative humidity-derived interference effects on the raw sensor response. Given the active flow of the gas sampling inlet and minimal residence time $(\sim 1 \mathrm{~s})$ of the sample air within the manifold, the RH and $T$ measurements recorded by the ARISense system closely track changes in ambient RH and $T$ conditions. Over the co-location period described here, temperature measurements inside the flow manifold were within $\sim 20 \%$ of the ambient values at all times. Note that the $\mathrm{CO}_{2}$ 
measurements are not discussed in this paper, which focuses on the four species measured by the electrochemical sensors, but will be addressed in a future paper.

The particle inlet is on the bottom face of the NEMA enclosure (Fig. 1, component C). Given the body of evidence implicating $\mathrm{PM}_{2.5}$ concentrations in adverse health outcomes (Lim et al., 2012), recent years have seen substantial growth in the development, evaluation, and deployment of low-cost OPCs (Holstius et al., 2014; Williams et al., 2014a; Han et al., 2017; Zikova et al., 2017). The principal measurement challenge of these devices is the minimum size detection limit, often $d_{\mathrm{p}} \geq 0.5 \mu \mathrm{m}$ (for devices that cost $\sim$ USD 250 to 800 ) or $d_{\mathrm{p}} \geq 1.0 \mu \mathrm{m}$ (cost $\sim$ USD 15 to 200 ). Unfortunately, given these size detection limits, such low-cost OPCs are inadequate when the accumulation mode aerosol size distribution peaks at $d_{\mathrm{p}} \leq 0.25 \mu \mathrm{m}$, which is typical in most urban locations. Low-cost OPC size detection limits also make nearfield particulate combustion emission characterization (i.e., near roadways) very challenging since the combustion mode of particles is typically $d_{\mathrm{p}}<0.1 \mu \mathrm{m}$. A detailed assessment of the ARISense particulate measurements in laboratory and field experiments will be provided in a subsequent paper.

This paper presents results for the four electrochemical sensors in a single ARISense system. Note that nominally identical electrochemical sensors can have widely different sensitivities and exhibit variable environmental interference effects. As a result, the specific calibration models described in this paper cannot be broadly applied to all ARISense systems. Until the reproducibility of electrochemical sensor manufacturing improves, system-specific HDMR models will need to be developed for each individual ARISense system to maintain robust sensor quantification metrics.

\subsection{Measurement site}

Two ARISense systems (indicated with yellow circles in Fig. 2) were deployed south of Boston, MA, from July to November 2016. This initial deployment of the ARISense systems was in conjunction with an existing four-node network (the Dorchester Air Quality Sensor System, DAQSS, project) established in January of 2016. The DAQSS node locations are indicated with green markers on the map. The neighborhoods of Roxbury and Dorchester are among Boston's largest and most economically diverse, including low-income residential areas interspersed with light and heavy industry, as well as the Interstate 93 (I-93) corridor which runs along the eastern edge of Dorchester. Given their location and activities therein, Dorchester and Roxbury experience a high frequency of automobile, commercial truck, and heavy duty diesel traffic, much of which is constrained to stop-and-go driving patterns on congested, narrow streets, in close proximity to housing and pedestrians. The original DAQSS deployment and initial ARISense proof-of-concept efforts were motivated by the need to assess the viability of lower-cost AQ-sensor systems in communities suffering from environmental health knowledge gaps, such as the unexplained doubling of the adult asthma rate in north Dorchester between 2001 and 2010 (Backus et al., 2012).

In order to validate our measurements, each ARISense system was co-located with a Massachusetts Department of Environmental Protection (MassDEP) air quality monitoring station (indicated with red circles on the map) for the duration of the present study. This paper presents ARISense and MassDEP reference data for the Roxbury site (left-hand yellow circle in Fig. 2) located adjacent to Harrison Avenue in Dudley Square (latitude +42.3295 , longitude -71.082619 ). Forthcoming papers will present results from the DAQSS project and the I-93 ARISense node location, covering lowercost AQ-sensor results over longer deployment timescales (18-24 months) and across multiple types of microenvironments in Roxbury and Dorchester.

\subsection{Reference data}

The MassDEP Roxbury air monitoring site (ID: 25-0250042), established in December 1998, hosts continuous and semi-continuous gas and particle measurements. The reference measurements used in this study include ozone $\left(\mathrm{O}_{3}\right.$; Teledyne Model T400 Photometric Ozone Analyzer; limit of detection [LOD] $<0.6 \mathrm{ppb}$ [parts per billion by volume]; root mean square "zero" noise $\left.\left[\mathrm{RMS}_{\text {zero }}\right]<0.3 \mathrm{ppb}\right)$, carbon monoxide (CO; Teledyne Model 300EU Carbon Monoxide Analyzer; LOD $<20 \mathrm{ppb} ; \mathrm{RMS}_{\mathrm{zero}} \leq 10 \mathrm{ppb}$ ), and nitrogen oxides (NO, $\mathrm{NO}_{x}, \mathrm{NO}_{2}$; Teledyne Model T200 Nitrogen Oxide Analyzer; LOD $=0.4 \mathrm{ppb} ; \mathrm{RMS}_{\mathrm{zero}}<0.2 \mathrm{ppb}$ ). The reference $\mathrm{NO} / \mathrm{NO}_{2}$ measurement is based on chemiluminescence. This method relies on converting NO molecules to $\mathrm{NO}_{2}$ via exposure to $\mathrm{O}_{3}$. Operationally, there are two measurements channels, one for $\mathrm{NO}$ alone and one for total $\mathrm{NO}_{x}$. In the $\mathrm{NO}_{x}$ channel, a catalytic-reactive converter is used to convert any existing $\mathrm{NO}_{2}$ molecules to $\mathrm{NO}$, prior to exposure to $\mathrm{O}_{3} \cdot \mathrm{NO}_{2}$ concentrations are determined by taking the difference between $\mathrm{NO}_{x}$ and NO. Additional on-site reference measurements include a meteorological tower (relative humidity, temperature, pressure, wind direction, wind speed, solar intensity; Met One), PM$_{2.5}$ (BAM, Beta Attenuation Mass Monitor), $\mathrm{PM}_{10}$, black carbon, and several offline gravimetric filter samplers including $\mathrm{PM}_{2.5}$ speciation. Given its level of instrumentation, the Roxbury location is considered an NCore site within the MassDEP network of monitoring stations across the state and provides critical data comparisons for determining the viability of lower-cost AQsensor systems. For the current study, MassDEP provided real-time (1 min average) pollutant concentration data files from its reference gas analyzers to permit data comparisons with the ARISense EC-sensor response under rapidly changing conditions of temperature, humidity, and ambient gas concentrations. 


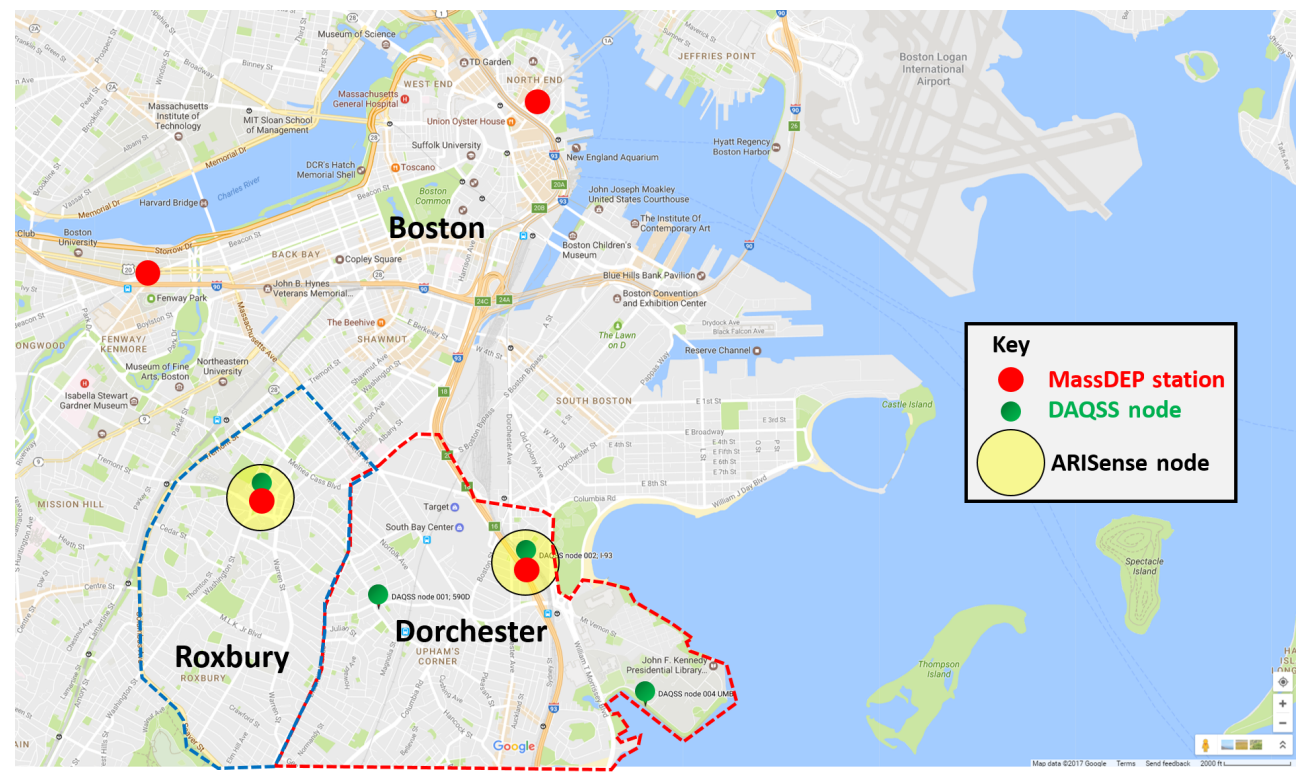

Figure 2. Map showing the locations of the two ARISense systems (yellow circles) and the four Boston metropolitan area DEP monitoring stations (red circles). The two ARISense systems were co-located with reference stations at the Harrison Avenue site (in Dudley Square, Roxbury) and Von Hillern Street site ( 35 feet from I-93 north) in Dorchester. The data presented in this paper were obtained from the Dudley Square location, an urban neighborhood site, primarily impacted by local combustion sources and vehicles operating on secondary routes in close proximity to the area. Green markers are shown to indicate the positions of four additional sensor nodes deployed as part of the Dorchester Air Quality Sensor System (DAQSS) project, which predated the development of ARISense.

\subsection{ARISense calibration}

Calibration is a critical issue for trusting the output of EC sensors. Recent papers (Lewis et al., 2016; Castell et al., 2017) have highlighted that the lack of rigorous calibration protocols for lower-cost AQ-sensors results in significant potential error when the sensor system is deployed in ambient conditions. For example, Mead et al. (2013) modeled the temperature-dependent baseline drift of an Alphasense NO sensor using an exponential curve fit through $24 \mathrm{~h}$ of ambient data. Their analysis revealed that temperature-derived baseline drift could exceed a $+600 \mathrm{ppb}$ bias if unaccounted for in their calibration (sampling between 20 and $28^{\circ} \mathrm{C}$ ). Considering that the ambient $\mathrm{NO}$ concentration range encountered in the current study was 0-200 ppb with sensor temperatures varying from $5-45^{\circ} \mathrm{C}$ ( 5 min averages), modeling the NO-B4 sensor temperature-derived interference is crucial to obtaining useful measurements from the sensor. As Mead et al. (2013) point out, when measuring gas concentrations at the ppb level, temperature and humidity interference effects have a first-order impact on quantification, whereas drift in sensitivity over time has second-order effects (much smaller in magnitude than temperature or humidity influence). Both first and second-order effects need to be correctly parameterized in order to apply lower-cost sensors to long-term $(\sim 18$ 36 months) ambient outdoor air quality measurements.

Alphasense provides some guidance to customers regarding calibration and temperature compensation of electro- chemical sensor response (Alphasense Application Note no. AAN 803-03, December 2014). This document highlights the utility of including a fourth electrode in their B4-series electrochemical sensors such as were used in this study. The purpose of this fourth electrode (called the auxiliary electrode, AUX) is to provide a real-time correction for environmentally derived interferences at the working electrode. The AUX electrode is comprised of an identical catalyst to that of the WE and is designed to mimic the WE's response to environmental changes such as temperature, pressure, and humidity. Since the AUX electrode is fully submerged in the electrolyte and directly below the WE, the AUX signal is theoretically "blind" to the target analyte gas species which readily oxidize or reduce at the WE surface (which is exposed to the air on one side and the electrolyte layer on the other). In an ideal world, a simple subtraction of the current generated at the AUX electrode from the current generated by the WE would provide a signal that is linearly proportional to the target analyte over the full concentration range of interest. Unfortunately, we have found that in practice the AUX electrodes in most sensors are not able to track the changes in the corresponding WE over the nominal operational temperatures of the system. Specifically, at sensor temperatures $>25^{\circ} \mathrm{C}$, the AUX electrode response lags behind that of the working electrode and, in some cases (CO-B4, for example), the WE and AUX electrode currents diverge as temperature increases (i.e., the WE current decreases with increasing temperature, while the AUX electrode current in- 
creases with increasing temperature). In this case, recording just the differential current without correction leads to an increasingly negative concentration error for $\mathrm{CO}$ at sensor temperatures above $25^{\circ} \mathrm{C}$. Alphasense provides users with a table in which, for each sensor model, the user can identify a correction constant to use to compensate for observed behavior at specified temperature ranges. At temperatures $\leq 20^{\circ} \mathrm{C}$ the Alphasense documentation shows that differential measurements remain fairly stable in comparison to the higher temperature conditions. The Alphasense approach to temperature compensation also requires the use of four static constants for each individual EC sensor - subtracting specific electronic and zero currents from both the WE and AUX electrodes, prior to calculating the difference. While there are some advantages to the additional information provided by the AUX electrode, at temperatures higher than $25^{\circ} \mathrm{C}$, the disparate response between the two electrodes can complicate quantification steps considerably.

In practice, we have found that the manufacturer's recommended WE and AUX electrode corrections do not lead to pollutant concentration values of acceptable accuracy for ambient air analysis. In addition, the EC-sensor response is impacted by other environmental conditions besides temperature, such as relative humidity and the concentrations of other gas-phase species. At the low concentrations present in the atmosphere (10-1000 s ppb), characterizing the full (multidimensional) interference response is critical to achieving reliable measurements. In this work we demonstrate the use of a multidimensional mathematical modeling approach (HDMR) that has the ability to adequately identify and quantify the complex EC-sensor response to multiple environmental variables and interfering gas species simultaneously.

\subsection{High-dimensional model representation (HDMR)}

The ARISense system uses high-dimensional model representation techniques to convert the raw sensor outputs into units of concentration (ppb). HDMR is a numerical method consisting of a general set of quantitative model assessments and analyses for capturing input-output system behavior without reliance on a physics-based model or the sensor manufacturer's empirical correction procedure. When applied to a set of experimental data (with sufficient variability), it can produce a mathematical model relating user-defined input variables to output variables of interest; the resulting model can capture the interdependencies of the variables and provide a mathematical description of the system that is otherwise difficult or impossible to describe with a physics-based model. The HDMR model can be used to identify and quantify which variables and variable interactions have the most impact on data reduction, relative to an identified output (i.e., reference concentration). In collaboration with the research group of Herschel Rabitz of Princeton University, Aerodyne has implemented HDMR methods in a software tool called
ExploreHD, providing graphical and command line user interfaces to HDMR algorithms.

The details of the HDMR algorithms used here are discussed in detail elsewhere ( $\mathrm{Li}$ and Rabitz, 2010; Sipilä et al., 2010; Li and Rabitz, 2012; Li et al., 2012). One of the key underlying tenets of the HDMR framework is that many input-output relationships for complex physical systems can be captured adequately by low-order combinations of input variables, even in systems with high dimensionality in input variables. Each component function provides an additive contribution to the overall model prediction. The modeling process involves three steps. In the first step, the user specifies a maximum variable interaction order (for example, a second-order HDMR model would allow component functions involving combinations of two input variables), and the HDMR algorithm considers orthogonal component functions (in this case, cubic polynomials) involving all possible variable combinations up to the maximum specified order. In the second step, a statistical analysis (using $F$ test) is performed to identify the input variables and combinations of input variables that contribute significantly to variation in the output of interest. In the final step, coefficients for component basis functions are calculated through a least squares analysis that minimizes the deviation between the HDMR model prediction and the training data. The coefficients and the associated orthogonal basis functions determined through the above analysis together define an HDMR model for the input-output relationship under consideration.

In the current study, the HDMR approach uses the raw EC-sensor output and environmental variables to model the multidimensional relationship between sensor output and the reference concentration. We used approximately $25 \%$ of the dataset to train the model. Sensor interference can be a product of the combined influences of temperature, humidity, pressure, non-analyte gas species, etc. The structure of the computational model accounts for both absolute (i.e., highest to lowest concentrations) and transient $(\Delta x / \Delta t$, or derivative) changes in the sampling conditions encountered by the sensor system. By spanning three seasons in the Northeastern United States, a wide range of environmental conditions was captured within the training window for the model. This emphasizes the advantage (i.e., variability in sampling conditions) and disadvantage (extended time span) of a field-based co-location approach to sensor calibration. The HDMR models developed in the current work were second order (examining all possible input parameter pairs) with orthogonal polynomial component functions allowed up to a degree of three (cubic) in each input variable.

The metrics used to evaluate the model are the slope and intercept of a linear least squares regression of the model output with the reference measurements, the coefficient of determination of the linear fit $\left(r^{2}\right)$, the root mean square error (RMSE), the mean absolute error (MAE), and the mean bias error (MBE). The equations for these metrics are given in Ta- 
ble $\mathrm{S} 1$ in the Supplement, and model-to-measurement results are summarized in Tables 2 and 3.

An example of how the HDMR model is developed for the NO-B4 sensor is provided in the Supplement. The left column of Table S2 lists all available input parameters, and the other columns denote which parameters were included in the input matrix for each model run. The bottom rows list the RMSE, MAE, and MBE for each model run for both the training data (model generation) and test data (model evaluation).

The data presented in this paper were recorded over a 4.5month sampling interval (7 July 2016-23 November 2016). All four electrochemical sensors used in this study were first removed from their packaging on 9 May 2016. That means that from the date of unpackaging, the sensors had aged $\sim 6.5$ months by 23 November. The manufacturer quoted lifetime for degradation of the signal to $50 \%$ is 36 months for the $\mathrm{CO}$ sensor and 24 months for the $\mathrm{NO}, \mathrm{NO}_{2}$, and $\mathrm{O}_{x}$ sensors. Given that these lifetimes are significantly longer than the deployment timescale analyzed here, we did not include a time-dependent sensitivity term in the input matrix of our HDMR model runs. The results presented here therefore assume that the sensitivity of each of the electrochemical sensors did not appreciably drift over the 4.5-month deployment. In subsequent studies we will analyze sensor response over longer deployment timescales (18 to 24 months) to investigate the importance of including a time-based parameter to track and correct for drift in sensor response with time.

\section{Results and discussion}

\subsection{ARISense meteorological and environmental data}

Continuous 5 min average non-pollutant data acquired with the ARISense system are shown in Fig. S2 in the Supplement, tracking ambient variability in temperature, pressure, humidity, solar intensity, ambient noise, wind speed, and wind direction at the Roxbury DEP monitoring site. The total sampling time span covers the transition from midsummer through late fall in the northeastern United States (July through November), with meteorological conditions changing from warmer and more humid to cooler and less humid. The ARISense system ran continuously throughout the sampling interval with the exception of a $\sim 1$-week period during which the node was physically removed from the site for a separate experiment. The directionality of the wind fields at this site is predominantly from the $\mathrm{N}$ to $\mathrm{NW}$ (red-maroon) with occasional NE flow (blue-purple). Temperature and humidity measurements shown reflect the conditions within the gas sampling flow cell of the integrated system, characterizing the environmental conditions at the surface of the electrochemical sensors. Such environmental measurements are critically important for reconciling the interference effects of ambient conditions, especially humid-
Table 1. Performance metrics for raw sensor output versus reference measurements.

\begin{tabular}{lrrrr}
\hline Sensor & $N_{\text {data points }}$ & $\begin{array}{r}Y \text { intercept } \\
\left(\mathrm{mV} \mathrm{ppb}^{-1}\right)\end{array}$ & Slope & $r^{2}$ \\
\hline $\mathrm{CO}-\mathrm{B} 4$ & 29507 & 3.26 & 0.25 & 0.78 \\
$\mathrm{NO}-\mathrm{B} 4$ & 33310 & 6.32 & 0.30 & 0.21 \\
$\mathrm{NO}_{2}$-B43F & 33363 & -27.4 & 0.29 & 0.18 \\
$\mathrm{O}_{x}$-B421 & 34077 & -131 & -0.48 & 0.12 \\
\hline
\end{tabular}

ity (water concentration) and temperature, on the raw signal from each electrochemical cell.

\subsection{ARISense electrochemical sensor data}

Figure 3 shows the time series for a $\sim 72 \mathrm{~h}$ period for the relative humidity; dew point temperature (panel a, solid and dashed lines, respectively); temperature (grey shaded area); and raw differential sensor output (dashed line), reference measurement (thick red dashed line), and model output (thin solid line) for the four electrochemical sensors (panels be). The raw differential sensor output is displayed as a voltage $(\Delta \mathrm{mV})$ which is linearly proportional to the difference in current generated within the electrochemical cell at each electrode (WE and AUX). The correlation plots between the raw EC-sensor output and the reference measurements are shown in Fig. 4a to d, with each data point colored by flowcell temperature. The intercept, slope, and $r^{2}$ for the linear regression indicated with a red line in Fig. 4 are listed in Table 1 .

The raw differential signals obtained from the CO-B4 sensor track reasonably well with the $\mathrm{CO}$ concentrations measured by the co-located DEP monitor (Figs. 3b and 4a), demonstrating the relatively small influence of ambient temperature, humidity, or other chemical species on this EC sensor. The NO sensor raw output also tracks reasonably well with the reference measurements (Figs. 3c and 4b) except at temperatures over $25^{\circ} \mathrm{C}$ when the EC sensor overestimates $\mathrm{NO}$ by a factor of 2 to 3 compared to lower temperatures. This demonstrates that the temperature dependences of the working and auxiliary electrodes in this NO sensor do not track one another at sample temperatures $>25^{\circ} \mathrm{C}$, and that additional temperature correction is necessary to obtain reasonable NO concentrations from the raw sensor outputs.

The $\mathrm{NO}_{2}$ and $\mathrm{O}_{3}$ raw sensor outputs do not track as well with the reference measurements $\left(r^{2}<0.2\right.$ in Fig. $4 \mathrm{c}$ and $\left.\mathrm{d}\right)$ The differential NO2-B43F sensor response (Figs. 3d and 4c) indicates a strong temperature dependence that is not compensated for by the auxiliary electrode, suggesting that additional temperature compensation algorithms could improve the result. The differential signal from the Ox-B421 electrode shows poor correlation with the reference data overall (Fig. 4d). There is some temperature dependence, but the additional variation suggests that other factors play an impor- 


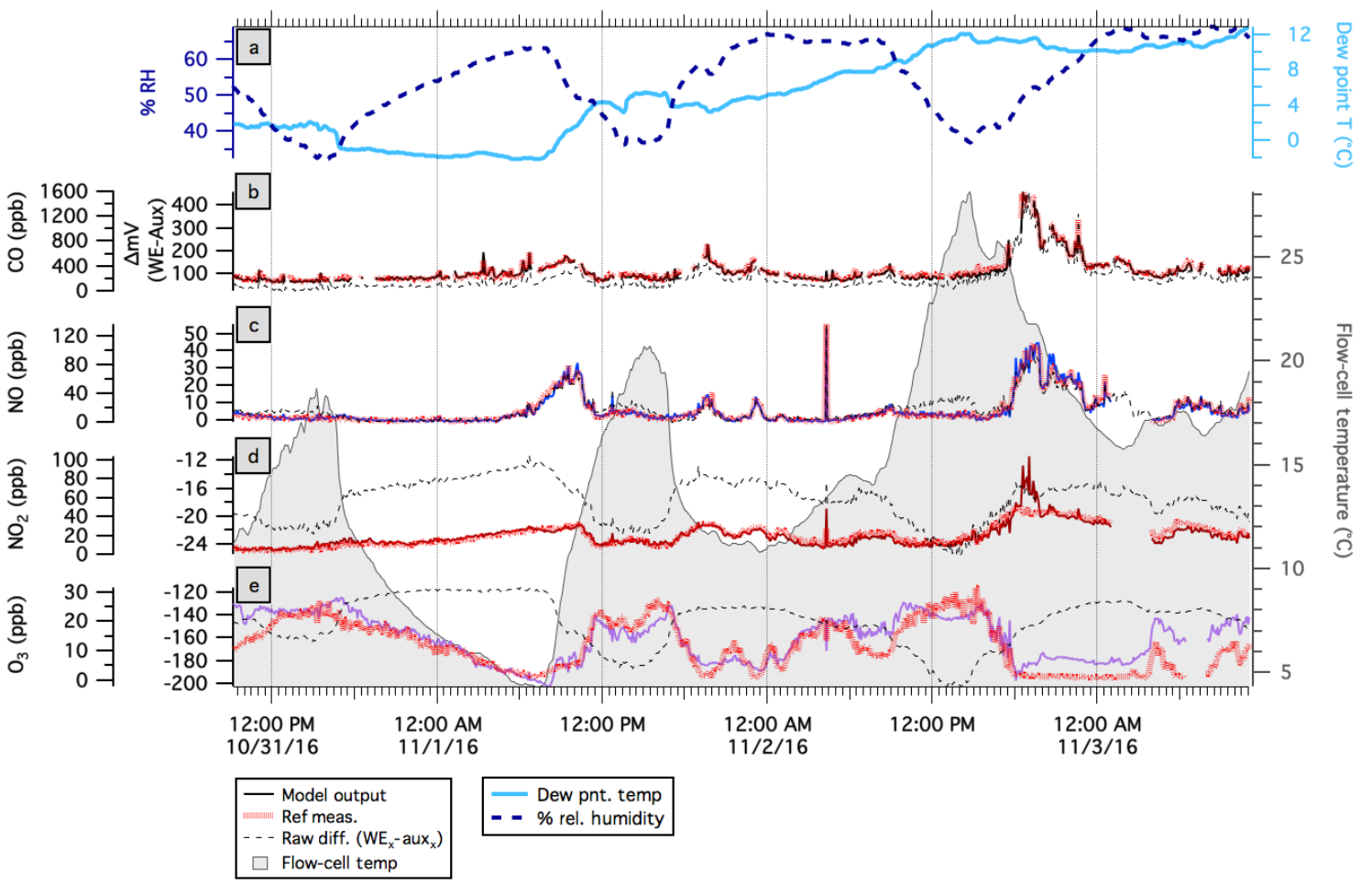

Figure 3. (a) Relative humidity (dashed blue line) and dew point temperature (solid blue line), (b-e) raw differential sensor output (dashed line), reference measurement (thick red line), and model output (thin line) for a 3-day period during the test part of the 4.5-month deployment. Temperature is indicated with the grey shaded area.

tant role. The Ox-B421 sensor is comprised of the same catalyst (working and auxiliary electrode material) as the NO2$\mathrm{B} 43 \mathrm{Fs}$ and is therefore sensitive to $\mathrm{NO}_{2}$ in addition to $\mathrm{O}_{3}$. The key difference between these two sensors is the presence of an $\mathrm{O}_{3}$-scrubbing filter upstream of the working electrode in the NO2-B43F sensor package. Laboratory results indicate that the Ox-B421 sensor is $\sim 2 \times$ more sensitive to $\mathrm{NO}_{2}$ than to $\mathrm{O}_{3}$ molecules.

As Fig. 3 shows, the magnitude of the interference signal due to temperature alone (for $\mathrm{NO}, \mathrm{NO}_{2}$, and $\mathrm{O}_{x}$ ) can easily mask real variation in pollutant concentrations. The raw signal behavior observed for each sensor type is different, underscoring the necessity of species-specific HDMR models to reconcile each sensor type's characteristic interferences. In addition, substantial $(\sim 2-3 \times)$ differences (in sensitivity and baseline) exist for batches of nominally identical sensors measuring the same concentration. Therefore, the HDMR models built for a given integrated system are specific to a given set of sensors and must be generated for each system separately to achieve reliable concentration data. Within the framework of an individual ARISense system, four distinct HDMR models are built, one for each EC-derived pollutant species of interest.

\subsection{HDMR analysis}

The training data for the HDMR model were chosen to provide comprehensive coverage of environmental variability spanning the July-November sampling interval. It was important to include (1) sensor responses to the range of gas concentrations encountered in ambient air (near-zero to high concentration transient spikes), (2) the range of temperatures and various rates of change in temperature, and (3) the range of measured water content of the sample air in the flow cell. The goal was to include a wide enough range of training data to avoid extrapolation errors when applying the model to the test dataset (all ambient co-location data not included in the training dataset). Figure S3 shows the distributions of temperature, reference measurement, dew point temperature, and relative humidity for the training data for the CO-B4 HDMR model, overlaid with corresponding distributions of the test data. We did not attempt to minimize the amount of ambient data used for training or vary the timing of the training data with respect to the test data. Approximately $25 \%$ of the full time series was used to generate the model (Table 2 and indicated with grey bars in Fig. 5). The exact fraction of data used for training was slightly different for each sensor due to differing calibration schedules for the reference measurements (which automatically excludes sensor data from the training or test datasets). For each sensor, the set of inputs included in 

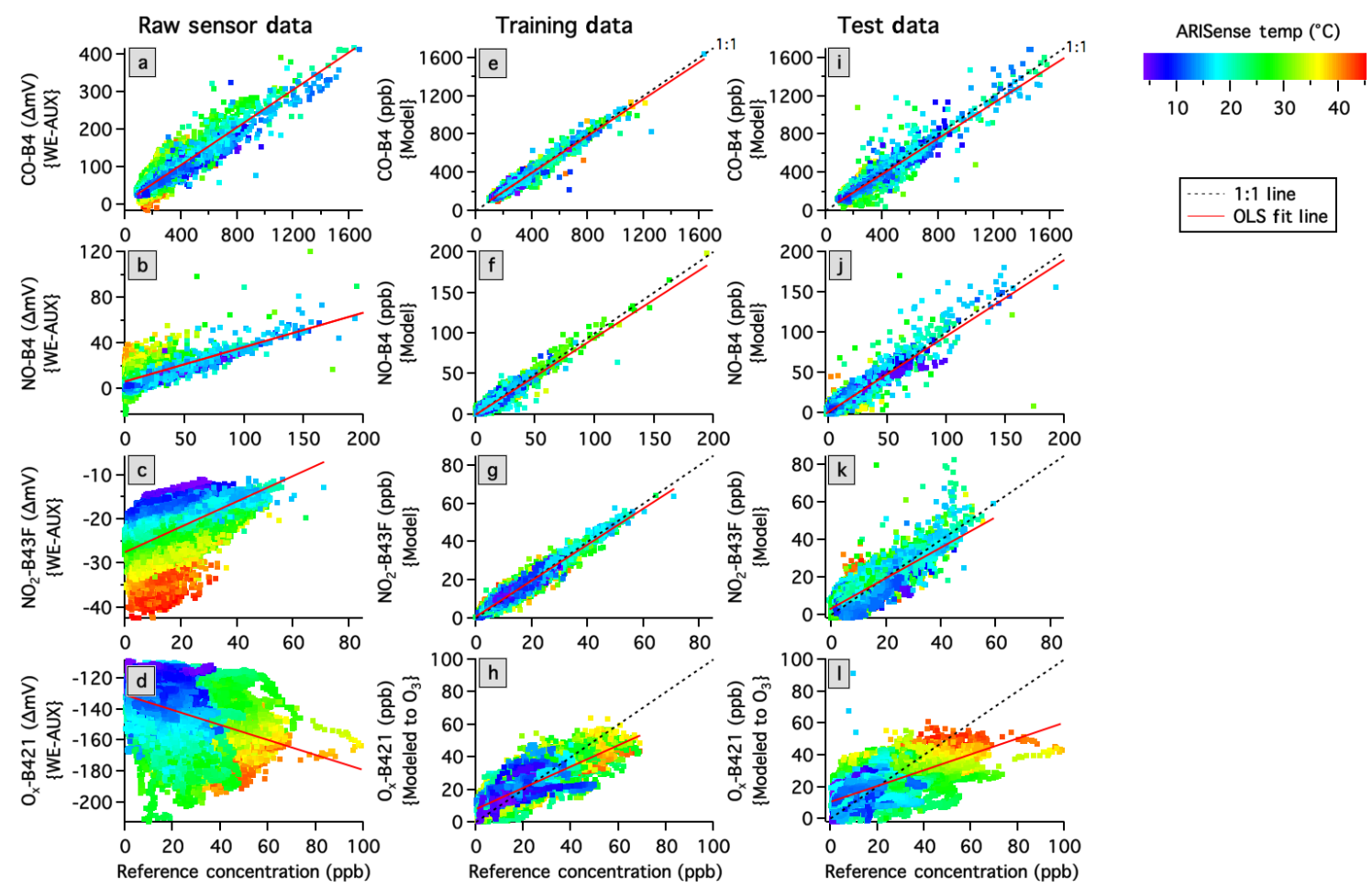

Figure 4. Correlation plots for all electrochemical sensors versus reference measurements for (a-d) raw sensor differential voltage signals, (e-h) model output concentrations for the training data ( $\sim 25 \%$ of data), and (i-l) model output concentrations for test data (remaining $\sim 75 \%$ of data). All data shown are $5 \mathrm{~min}$ average values with each data point colored by flow-cell temperature. The linear regression fit line (solid red line) is shown in all panels, and a $1: 1$ line (dashed black line) is shown in panels (e)-(l).

Table 2. Performance metrics for model output versus reference measurements for training data.

\begin{tabular}{lrrrrrrrr}
\hline Sensor & $N_{\text {data points }}$ & $\begin{array}{r}Y \text { intercept } \\
(\mathrm{ppb})\end{array}$ & Slope & $r^{2}$ & $\begin{array}{r}\text { RMSE } \\
(\mathrm{ppb})\end{array}$ & $\begin{array}{r}\text { MAE } \\
(\mathrm{ppb})\end{array}$ & $\begin{array}{r}\text { MBE } \\
(\mathrm{ppb})\end{array}$ & $\begin{array}{r}f_{\text {train }}^{*} \\
(\%)\end{array}$ \\
\hline $\mathrm{CO}-\mathrm{B} 4$ & 7974 & 9.19 & 0.96 & 0.96 & 25.4 & 16.7 & 0.02 & $27.0 \%$ \\
$\mathrm{NO}-\mathrm{B} 4$ & 7974 & 0.46 & 0.94 & 0.94 & 3.37 & 2.17 & -0.01 & $23.9 \%$ \\
$\mathrm{NO}_{2}$-B43F & 7874 & 0.80 & 0.94 & 0.94 & 2.29 & 1.73 & -0.05 & $23.6 \%$ \\
$\mathrm{O}_{x}$-B421 & 9071 & 8.34 & 0.65 & 0.65 & 8.24 & 6.22 & 0.03 & $26.6 \%$ \\
\hline
\end{tabular}

$* f_{\text {train }}=N_{\text {training }} / N_{\text {total }} \times 100$

the input data matrix was optimized as described in Sect. 2.5 and the Supplement.

Correlation plots of model-derived pollutant concentrations and reference concentrations for the training data are shown in the middle panels (e-h) of Fig. 4. The linear regression fit (solid red line) and a 1:1 line (dashed black line) are shown for all species, and all data points are colored by flowcell temperature. The performance metrics are presented in Table 2. The lack of a temperature-dependent rainbow in the scatter plots shown in Fig. $4 \mathrm{e}-\mathrm{h}$ (with the exception of $\mathrm{O}_{3}$, for which ambient concentrations are expected to be temperature dependent) indicates that the model has effectively compensated for the variable temperature-dependent response of the working and auxiliary electrodes within each cell. The re- maining scatter in the correlation plots is random noise attributed to the electrodes themselves and the ARISense electronics. The high correlation coefficients $\left(r^{2}=0.94-0.96\right)$ for $\mathrm{CO}, \mathrm{NO}$, and $\mathrm{NO}_{2}$ indicate that, when trained appropriately, the HDMR model provides improved compensation for the environmental interferences that complicate interpretation of raw EC-sensor outputs. The much lower correlation coefficient $\left(r^{2}=0.65\right)$ for $\mathrm{O}_{x}$ suggests that additional parameters may be needed to fully explain the behavior of this EC sensor. The updated version of the Ox-B4 sensor (Ox-B431) may also improve the ability of HDMR to effectively model the $\mathrm{O}_{x}$ interferences.

The HDMR models were then used to analyze the remaining $\sim 75 \%$ of the data (the test set). The correlation plots 


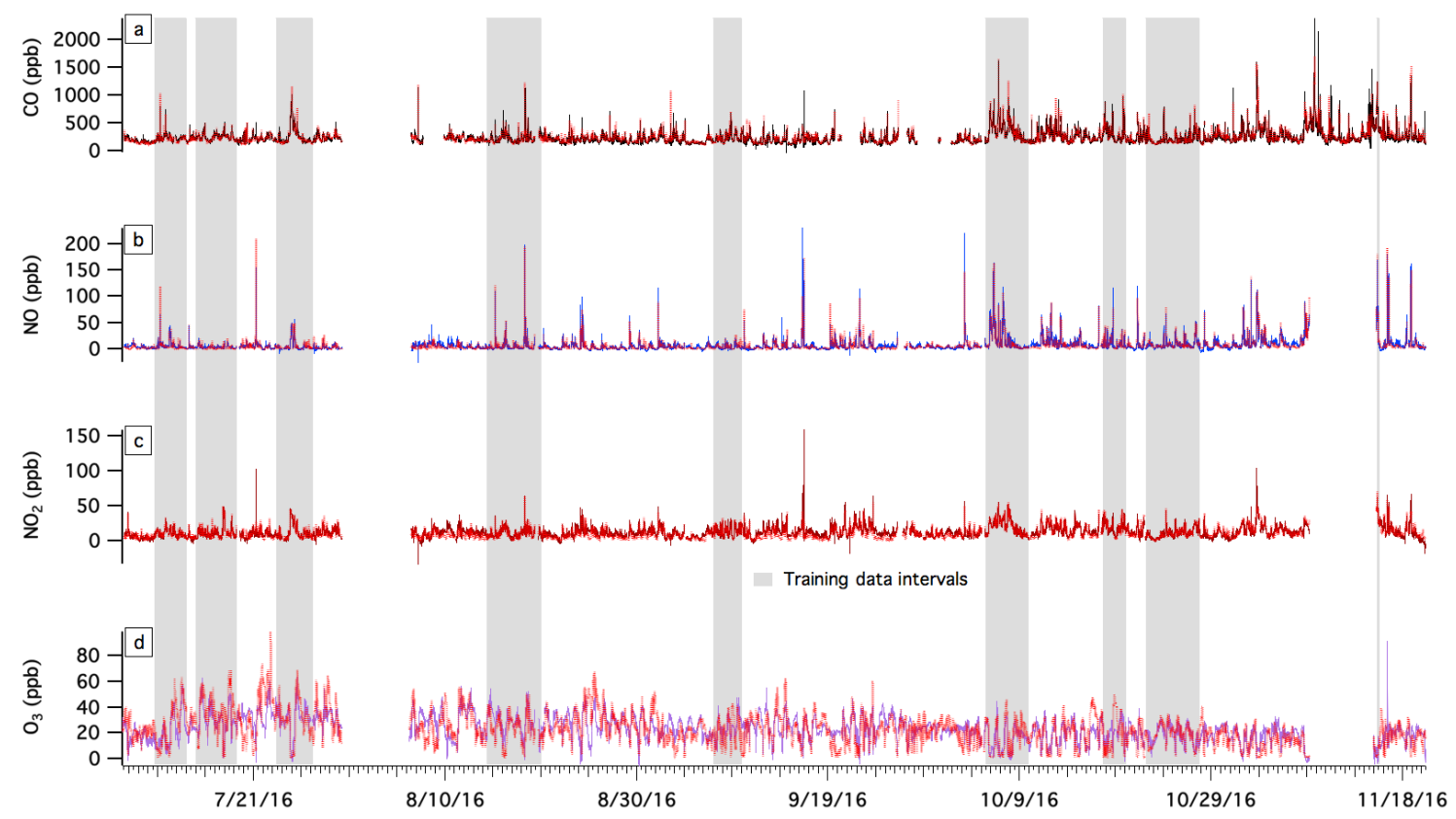

Figure 5. Time series of $5 \mathrm{~min}$ averages of the model output (sensor) and reference gas concentrations. Grey shaded areas indicate time periods over which the model was trained. A unique set of input parameters was used to train the HDMR model for each of the different electrochemical cells. Approximately $25 \%$ of the data were used for training and the remaining $75 \%$ was used to test the models.

Table 3. Performance metrics for model output versus reference measurements for test data ( 5 min average temporal resolution).

\begin{tabular}{lrrrrrrr}
\hline Sensor & $N_{\text {data points }}$ & $\begin{array}{r}Y \text { intercept } \\
(\mathrm{ppb})\end{array}$ & Slope & $r^{2}$ & $\begin{array}{r}\text { RMSE } \\
(\mathrm{ppb})\end{array}$ & $\begin{array}{r}\text { MAE } \\
(\mathrm{ppb})\end{array}$ & $\begin{array}{r}\text { MBE } \\
(\mathrm{ppb})\end{array}$ \\
\hline $\mathrm{CO}-\mathrm{B} 4$ & 21533 & 3.98 & 0.94 & 0.88 & 39.2 & 24.8 & -10.4 \\
$\mathrm{NO}-\mathrm{B} 4$ & 25356 & 1.29 & 0.94 & 0.84 & 4.52 & 2.83 & 0.97 \\
$\mathrm{NO}_{2}-\mathrm{B} 43 \mathrm{~F}$ & 25489 & 3.26 & 0.81 & 0.69 & 4.56 & 3.45 & 1.20 \\
$\mathrm{O}_{x}$-B421 & 25006 & 13.1 & 0.47 & 0.39 & 9.71 & 7.34 & 0.78 \\
\hline
\end{tabular}

for the model output versus the reference measurement for the test data are shown in Fig. $4 \mathrm{i}-1$ and the performance metrics are presented in Table 3. Figure 5 shows the time series for the $5 \mathrm{~min}$ averages of the modeled (sensor) and reference gas concentrations, with the training data intervals indicated with grey bars. The high correlation coefficient for $\mathrm{CO}$ and $\mathrm{NO}\left(r^{2}>0.8\right)$ and moderate correlation coefficient for $\mathrm{NO}_{2}$ $\left(r^{2}=0.69\right)$ indicate the strength of the model at capturing the ambient variability in pollutant concentrations encountered at the site, despite wide variations in ambient temperature and humidity over the changing seasons.

The higher scatter in the $\mathrm{O}_{3}$ correlation plot, and correspondingly low $r^{2}=0.39$, might be due to the fact that $\mathrm{O}_{3}$ is obtained by training the Ox-B421 sensor output to reference $\mathrm{O}_{3}$ alone; the $2: 1$ sensitivity ratio for $\mathrm{NO}_{2}$ vs. $\mathrm{O}_{3}$ of the Ox-B421 means that the variability in ambient $\mathrm{NO}_{2}$ concentrations adds considerable noise to the Ox-B421 sensor signal. The input matrix for the Ox-B421 HDMR model includes the raw data captured with the NO2-B43F sensor, but the inclusion of this additional information only marginally improves the reduction of the $\mathrm{Ox}-\mathrm{B} 421$ data to $\mathrm{O}_{3}$ concentration. This may be due to a different time response of the $\mathrm{O}_{x}$ sensor used in this study compared to the $\mathrm{NO}_{2}$ sensor.

It should be noted that the Ox-B421 sensor is not the latest version released by Alphasense and improvements may be realized with the design of their most recent model (OxB431). The results of Zimmerman et al. (2017) for the OxB431 sensor have a much better $r^{2}=0.86$ (see Table 4), while their results are comparable to ours for the $\mathrm{CO}$ and $\mathrm{NO}_{2}$ sensors. These considerations highlight the iterative and rapidly evolving nature of lower-cost AQ-sensor components. Lower-cost air-quality-sensor quantification will likely improve over the coming years through advances at both the component manufacturer level (e.g., Alphasense Ltd. improving materials chemistry and the catalyst and sensor design) and system integrator level (e.g., Aerodyne Research, Inc., further developing ARISense HDMR interference modeling through laboratory and field-based measurements). 
Table 4. Comparisons to published results utilizing integrated multi-pollutant systems comprised of Alphasense electrochemical sensors.

\begin{tabular}{|c|c|c|c|c|c|c|c|}
\hline Studies & $\begin{array}{r}\text { Temporal } \\
\text { resolution }(\mathrm{min})\end{array}$ & $N_{\text {data points }}$ & Slope & $r^{2}$ & $\begin{array}{r}\mathrm{RMSE} \\
(\mathrm{ppb})\end{array}$ & $\begin{array}{l}\text { MAE } \\
(\mathrm{ppb})\end{array}$ & $\begin{array}{l}\mathrm{MBE} \\
(\mathrm{ppb})\end{array}$ \\
\hline \multicolumn{8}{|l|}{ CO sensor } \\
\hline Jiao et al. $(2016)^{1}$ & 60 & $2640-2664^{\#}$ & $<0.001$ & $0.63-0.68$ & NR & NR & NR \\
\hline Castell et al. $(2017)^{2}$ & 15 & $6912^{\#}$ & NR & 0.36 & 170.99 & NR & -147.21 \\
\hline Zimmerman et al. $(2017)^{3}$ & 15 & $3936^{\#}$ & 0.86 & 0.91 & NR & 38 & 0.1 \\
\hline This work ${ }^{4}(\mathrm{CO}-\mathrm{B} 4)$ & 5 & 21533 & 0.94 & 0.88 & 32.9 & 24.8 & -10.4 \\
\hline \multicolumn{8}{|l|}{ NO sensor } \\
\hline Jiao et al. (2016) & 60 & $2640-2664^{\#}$ & $0.883-0.892$ & $0.77-0.87$ & NR & NR & NR \\
\hline Castell et al. (2017) & 15 & $6912^{\#}$ & NR & 0.74 & 16.35 & NR & -0.54 \\
\hline This work (NO-B4) & 5 & 25356 & 0.94 & 0.84 & 4.52 & 2.83 & 0.97 \\
\hline \multicolumn{8}{|l|}{ NO2 sensor } \\
\hline Jiao et al. (2016) & 60 & $2640-2664^{\#}$ & NR & $0.02-0.10$ & NR & NR & NR \\
\hline Castell et al. (2017) & 15 & $6912^{\#}$ & NR & 0.24 & 30.27 & NR & 13.30 \\
\hline Zimmerman et al. (2017) & 15 & $2304^{\#}$ & 0.64 & 0.67 & NR & 3.48 & -0.4 \\
\hline This work (NO2-B43F) & 5 & 25489 & 0.81 & 0.69 & 4.56 & 3.45 & 1.20 \\
\hline \multicolumn{8}{|l|}{ Ox sensor } \\
\hline Jiao et al. (2016) & 60 & $2640-2664^{\#}$ & NR & $0.15-0.20$ & NR & NR & NR \\
\hline Castell et al. (2017) & 15 & $6912^{\#}$ & NR & 0.29 & 22.20 & NR & 6.76 \\
\hline Zimmerman et al. (2017)* & 15 & $3648^{\#}$ & 0.82 & 0.86 & NR & 3.36 & -0.14 \\
\hline This work (Ox-B421) & 5 & 25006 & 0.47 & 0.39 & 9.71 & 7.34 & 0.78 \\
\hline
\end{tabular}

$\mathrm{NR}=$ not reported in paper. ${ }^{\#} N$ calculated assuming $100 \%$ duty cycle over specified days of co-location for each study. ${ }^{1}$ Results obtained from two AQMesh integrated sensor systems (gen. 3) deployed in Decatur, Georgia, US. ${ }^{2}$ Statistical metrics correspond to average of 24 co-located AQMesh systems deployed in Kirkeveien, Norway. ${ }^{3}$ Average test results from 19 Real-time Affordable Multi-Pollutant (RAMP) systems co-located in Pittsburgh, Pennsylvania, US. ${ }^{4}$ Single ARISense system deployed in Dorchester, Massachusetts, US. * Ox-B431 sensor.

Examination of the model output for $72 \mathrm{~h}$ of the test data in Fig. 3 gives additional clues for improving the model. In Fig. 3d at $\sim 19: 00$ on 2 November 2016, the model $\mathrm{NO}_{2}$ exceeds the reference $\mathrm{NO}_{2}$ by a factor of $\sim 2$ during a period of rapidly decreasing temperature and increasing RH. This underscores that the rate of change of input parameters may be important in the model, in addition to the absolute values. Figure $3 \mathrm{e}$ also suggests that the HDMR model for $\mathrm{O}_{x}$ struggles during times of rapidly changing temperature, particularly when the $\mathrm{O}_{3}$ concentration is low $(<3 \mathrm{ppb})$. Future development of HDMR models to support ARISense quantification will include derivatives of influential variables as explicit inputs and model optimization for low concentrations $(<5 \mathrm{ppb})$ for species such as $\mathrm{NO}_{2}$ and $\mathrm{O}_{3}$.

Table 4 presents a comparison of evaluation statistics for this work and three other recent studies that evaluated Alphasense electrochemical sensors through extended co-located field measurements. One important distinction among the papers summarized in the table is that our work and the work of Zimmerman et al. (2017) are obtained from an AQ system integrator perspective (building and evaluating interference models), whereas the work of Jiao et al. (2016) and Castell et al. (2017) are end-user evaluations, reliant on the manufacturer's calibrated outputs. The duration of each co-location, temporal resolution of the reported sensor measurements, and variability in pollutant concentrations (and environmental conditions) at each site strongly influence the performance metrics of the electrochemical sensors. Results from the ARISense HDMR model at 5 min resolution show significant improvement relative to Jiao et al. (2016) and Castell et al. (2017) for all measured species and comparable metrics to Zimmerman et al. (2017) for $\mathrm{CO}$ and $\mathrm{NO}_{2}$. As discussed previously, the HDMR model output for the Ox-B421 sensor underperforms the Zimmerman et al. (2017) Ox-B431 model.

While Figures 4 and 5 illustrate that the system is capable of determining valid gas-phase concentrations across a wide range of environmental variability in temperature, $\mathrm{RH}$, and absolute concentrations, it does not speak to the longer-term stability of the sensors (e.g., how much does the baseline and sensitivity of each electrochemical sensor change with time). However, it should be noted that sensor aging cannot have had a major impact on the data reported here or it would have been impossible for the HDMR model to converge this well without including electrode age as one of the input variables. For the models developed in this work, each data point for 
each variable had equal weight, whether it was at the beginning, middle, or end of the 4.5-month deployment. It is to be expected that aging of EC sensors will change their sensitivities, due to electrolyte evaporation or dilution, entrapment of contaminants, and repeated exposure to wide swings in $T$ or RH. It will be important to establish the time span over which a given set of EC sensors (and the HDMR model of that sensor set) can be expected to return reliable pollutant concentration values, using a longer duration (18-24 months) ambient dataset; such a study is in progress.

\section{Conclusion}

This study demonstrates that lower-cost air-quality-sensor systems can adequately characterize ambient urban pollution concentrations on rapid $(5 \mathrm{~min})$ timescales, underscoring the potential of integrated sensor systems to add a highly resolved local AQ data layer to existing pollution monitoring infrastructure. The ARISense system is a first step toward understanding the extent to which quantification efforts can yield useful results from such systems. Training electrochemical sensor measurements of $\mathrm{CO}, \mathrm{NO}, \mathrm{NO}_{2}$, and $\mathrm{O}_{3}$ with a high-dimensional model representation method provided $5 \mathrm{~min}$ average RMSE values of 39.2 , 4.52, 4.56, and $9.71 \mathrm{ppb}$ for $\mathrm{CO}, \mathrm{NO}, \mathrm{NO}_{2}$, and $\mathrm{O}_{3}$, respectively. Results indicate that HDMR can effectively model interference effects derived from the variable ambient gas concentrations in an urban setting and changing environmental conditions encountered over three seasons in the Northeastern United States (temperature $=23.4 \pm 8.5^{\circ} \mathrm{C}$, spanning 4.1 to $45.2{ }^{\circ} \mathrm{C}$; and relative humidity $=50.1 \pm 15.3 \%$, spanning 9.8-79.9\%).

Referring back to the map displayed in Fig. 2, it is striking to consider that only four official monitoring stations exist within the Boston metropolitan area (population 700000 ). With regard to the Roxbury DEP site 1 min average reference data, it is important to note that $1 \mathrm{~min}$ data files are not typically reported or accessible from regional air quality monitoring sites. Instead, pollutant concentrations are usually reported on 1,8 , or $24 \mathrm{~h}$ averages in accordance with the operational constraints of the measurement device and relevant air quality regulations being enforced. This sampling paradigm is consistent with the regional focus of federal and state monitoring goals, and financial constraints imposed due to the expense of the instrumentation and operating costs of a given AQ monitoring station. But as one considers the pollutant sources that contribute to their local area, disproportionate pollution impacts emerge in some neighborhoods more than others. Across urban landscapes, air pollution is inherently heterogeneous - subject to sharp concentration gradients over fast (sub-minute) and short (100s of meters) scales. In order to establish a more rigorous assessment of such disparate impacts, distributed sensor networks are needed to achieve high enough spatial resolution to inform intra- neighborhood differences in air quality. Through such advances, researchers, regulators, and community members can improve their understanding of the pollutant sources that dictate their local AQ. As sensor technologies (and calibrationmodeling efforts) continue to improve, the local AQ data layer could play a key role toward empowering environmental justice advocates to initiate change and improve environmental public health.

It cannot be overstated that EC-sensor systems such as ARISense can return reliable data only if calibrated over the full range of pollutant concentrations and meteorological parameters that will be encountered when they are deployed. In the present study, co-location of the ARISense system with the MassDEP reference monitors, coupled with variability of natural processes and anthropogenic activities, supplied the necessary range of conditions over the 4.5-month span of the study. In the future, we expect to compress that training period, using a controlled-environment laboratory chamber and mixes of calibration gases representative of the pollutants encountered under ambient conditions. This compression of the training period is especially important when addressing the challenges of sensor-to-sensor variability, finite ( $<24-36$ months) sensor lifetime, and premature damage or failures that will require rapid replacement and retraining of integrated systems.

Data availability. The data are available upon request to Eben S. Cross (escross@ aerodyne.com).

\section{The Supplement related to this article is available online at https://doi.org/10.5194/amt-10-3575-2017-supplement.}

Competing interests. Eben S. Cross, Leah R. Williams, David K. Lewis, Gregory R. Magoon, Timothy B. Onasch, Douglas R. Worsnop, and John T. Jayne are employees of Aerodyne Research, Inc., which is developing and commercializing the ARISense system used in this study.

Acknowledgements. The authors would like to thank the staff at the Massachusetts Department of Environmental Protection for their support, including access to the DEP monitoring stations and raw $1 \mathrm{~min}$ data from the reference gas analyzers used in the current study. We are especially grateful to John Lane, Leslie Collyer, Emmy Andersen, Patrick Shea, and Thomas McGrath at MassDEP. ARISense builds upon the DAQSS network; Eben S. Cross acknowledges David Hagan for his support of the DAQSS project (electronics, backend development, and system integration) and for helpful discussions regarding advanced modeling approaches to sensor quantification. Eben S. Cross thanks Ann Backus and Gary Adamkiewicz for their collaboration on the DAQSS project (NIEHS grant P30 ES000002 via the Community Outreach 
and Engagement Core, COEC, of the HSPH NIEHS Center for Environmental Health). ESC also thanks Stephen Prescott for his assistance with the ARISense mechanical-electrical assembly, Xavier Cabral for his contributions to the initial electrical design, and Conor Mackinson and Wade Robinson for their mechanical design contributions to the ARISense package. The authors also thank the reviewers for their insightful comments which helped improve the final manuscript.

Edited by: Gavin Phillips

Reviewed by: three anonymous referees

\section{References}

Backus, A., Terrell, K., Wool, J., and Straubel, M.: Health, Environment, Community - A Tour of Dorchester and Surrounding Neighborhoods for Asthma Prevention and Health Equity, Harvard School of Public Health, NIEHS Center for Environmental Health, and GreenDorchester, 2012.

Borrego, C., Costa, A., Ginja, J., Amorim, M., Coutinho, M., Karatzas, K., Sioumis, T., Katsifarakis, N., Konstantinidis, K., and De Vito, S.: Assessment of air quality microsensors versus reference methods: The EuNetAir joint exercise, Atmos. Environ., 147, 246-263, 2016.

Castell, N., Dauge, F. R., Schneider, P., Vogt, M., Lerner, U., Fishbain, B., Broday, D., and Bartonova, A.: Can commercial low-cost sensor platforms contribute to air quality monitoring and exposure estimates?, Environ. Int., 99, 293-302, https://doi.org/10.1016/j.envint.2016.12.007, 2017.

EPA: Evaluation of Emerging Air Pollution Sensor Performance, available at: https://www.epa.gov/air-sensor-toolbox/ evaluation-emerging-air-pollution-sensor-performance, 2017.

Hagan, D. H., Issacman-Vanwertz, G., Franklin, J. P., Wallace, L. M. M., Kocar, B. D., Heald, C. L., and Kroll, J. H.: Calibration and assessment of electrochemical air quality sensors by colocation with reference-grade instruments, Atmos. Meas. Tech. Discuss., https://doi.org/10.5194/amt-2017-296, in review, 2017.

Han, I., Symanski, E., and Stock, T. H.: Feasibility of using low-cost portable particle monitors for measurement of fine and coarse particulate matter in urban ambient air, J. Air Waste Ma., 67, 330-340, 2017.

Holstius, D. M., Pillarisetti, A., Smith, K. R., and Seto, E.: Field calibrations of a low-cost aerosol sensor at a regulatory monitoring site in California, Atmos. Meas. Tech., 7, 1121-1131, https://doi.org/10.5194/amt-7-1121-2014, 2014.

Jiao, W., Hagler, G., Williams, R., Sharpe, R., Brown, R., Garver, D., Judge, R., Caudill, M., Rickard, J., Davis, M., Weinstock, L., Zimmer-Dauphinee, S., and Buckley, K.: Community Air Sensor Network (CAIRSENSE) project: evaluation of low-cost sensor performance in a suburban environment in the southeastern United States, Atmos. Meas. Tech., 9, 5281-5292, https://doi.org/10.5194/amt-9-5281-2016, 2016.

Kumar, P., Morawska, L., Martani, C., Biskos, G., Neophytou, M., Di Sabatino, S., Bell, M., Norford, L., and Britter, R.: The rise of low-cost sensing for managing air pollution in cities, Environ. Int., 75, 199-205, 2015.

Lewis, A. C. and Edwards, P. M.: Validate personal air-pollution sensors, Nature, 535, 29-31, 2016.
Lewis, A. C., Lee, J. D., Edwards, P. M., Shaw, M. D., Evans, M. J., Moller, S. J., Smith, K. R., Buckley, J. W., Ellis, M., Gillot, S. R., and White, A.: Evaluating the performance of low cost chemical sensors for air pollution research, Faraday Discuss., 189, 85-103, 2016.

Li, G. and Rabitz, H.: D-MORPH regression: application to modeling with unknown parameters more than observation data, J. Math. Chem., 48, 1010-1035, 2010.

Li, G. and Rabitz, H.: General formulation of HDMR component functions with independent and correlated variables, J. Math. Chem., 50, 99-130, 2012.

Li, G., Rey-de-Castro, R., and Rabitz, H.: D-MORPH regression for modeling with fewer unknown parameters than observation data, J. Math. Chem., 50, 1747-1764, https://doi.org/10.1007/s10910012-0004-z, 2012.

Lim, S., Vos, T., Flaxman, A., Danaei, G., Shibuya, K., AdairRohani, H., AlMazroa, M. A., Amann, M., Anderson, H. R., Andrews, K. G., Aryee, M., Atkinson, C., Bacchus, L. J., Bahalim, A. N., Balakrishnan, K., Balmes, J., Barker-Collo, S., Baxter, A., Bell, M. L., Blore, J. D., Blyth, F., Bonner, C., Borges, G., Bourne, R., Boussinesq, M., Brauer, M., Brooks, P., Bruce, N. G., Brunekreef, B., Bryan-Hancock, C., Bucello, C., Buchbinder, R., Bull, F., Burnett, R. T., Byers, T. E., Calabria, B., Carapetis, J., Carnahan, E., Chafe, Z., Charlson, F., Chen, H., Chen, J. S., Cheng, A. T.-A., Child, J. C., Cohen, A., Colson, K. E., Cowie, B. C., Darby, S., Darling, S., Davis, A., Degenhardt, L., Dentener, F., Des Jarlais, D. C., Devries, K., Dherani, M., Ding, E. L., Dorsey, E. R., Driscoll, T., Edmond, K., Eltahir Ali, S., Engell, R. E., Erwin, P. J., Fahimi, S., Falder, G., Farzadfar, F., Ferrari, A., Finucane, M. M., Flaxman, S., Fowkes, F. G. R., Freedman, G., Freeman, M. K., Gakidou, E., Ghosh, S., Giovannucci, E., Gmel, G., Graham, K., Grainger, R., Grant, B., Gunnell, D., Gutierrez, H. R., Hall, W., Hoek, H. W., Hogan, A., Hosgood, H. D., III, Hoy, D., Hu, H., Hubbell, B. J., Hutchings, S. J., EIbeanusi, S., Jacklyn, G. L., Jasrasaria, R., Jonas, J. B., Kan, H., Kanis, J. A., Kassebaum, N., Kawakami, N., Khang, Y.-H., Khatibzadeh, S., Khoo, J.-P., Kok, C., Laden, F., Lalloo, R., Lan, Q., Lathlean, T., Leasher, J. L., Leigh, J., Li, Y., Lin, J. K., Lipshultz, S. E., London, S., Lozano, R., Lu, Y., Mak, J., Malekzadeh, R., Mallinger, L., Marcenes, W., March, L., Marks, R., Martin, R., McGale, P., McGrath, J., Mehta, S., Memish, Z. A., Mensah, G. A., Merriman, T. R., Micha, R., Michaud, C., Mishra, V., Hanafiah, K. M., Mokda, A. A., Morawska, L., Mozaffarian, D., Murphy, T., Naghavi, M., Neal, B., Nelson, P. K., Nolla, J. M., Norman, R., Olives, C., Omer, S. B., Orchard, J., Osborne, R., Ostro, B., Page, A., Pandey, K. D., Parry, C. D. H., Passmore, E., Patra, J., Pearce, N., Pelizzari, P. M., Petzold, M., Phillips, M. R., Pope, D., Pope, C. A., III, Powles, J., Rao, M., Razavi, H., Rehfuess, E. A., Rehm, J. T., Ritz, B., Rivara, F. P., Roberts, T., Robinson, C., Rodriguez-Portales, J. A., Romieu, I., Room, R., Rosenfeld, L. C., Roy, A., Rushton, L., Salomon, J. A., Sampson, U., SanchezRiera, L., Sanman, E., Sapkota, A., Seedat, S., Shi, P., Shield, K., Shivakoti, R., Singh, G. M., Sleet, D. A., Smith, E., Smith, K. R., Stapelberg, N. J. C., Steenland, K., Stöckl, H., Stovner, L. J., Straif, K., Straney, L., Thurston, G. D., Tran, J. H., Van Dingenen, R., Donkelaar, A., Veerman, J. L., Vijayakumar, L., Weintraub, R., Weissman, M. M., White, R. A., Whiteford, H., Wiersma, S. T., Wilkinson, J. D., Williams, H. C., Williams, W., Wilson, N., Woolf, A. D., Yip, P., Zielinski, J. M., Lopez, A. D., 
Murray, C. J. L., and Ezzati, M.: A comparative risk assessment of burden of disease and injury attributable to 67 risk factors and risk factor clusters in 21 regions, 1990-2010: a systematic analysis for the Global Burden of Disease Study 2010, Lancet, 380, 2224-2260, 2012.

Masson, N., Piedrahita, R., and Hannigan, M.: Quantification method for electrolytic sensors in long-term monitoring of ambient air quality, Sensors, 15, 27283-27302, https://doi.org/10.3390/s151027283, 2015.

McKercher, G. R., Salmond, J. A., and Vanos, J. K.: Characteristics and applications of small, portable gaseous air pollution monitors, Environ. Pollut., 223, 102-110, https://doi.org/10.1016/j.envpol.2016.12.045, 2017.

Mead, M., Popoola, O., Stewart, G., Landshoff, P., Calleja, M., Hayes, M., Baldovi, J., McLeod, M., Hodgson, T., Dicks, J., Lewis, A. C., Cohen, J., Baron, R., Saffell, J., and Jones, R.: The use of electrochemical sensors for monitoring urban air quality in low-cost, high-density networks, Atmos. Environ., 70, 186-203, 2013.

Mueller, M., Meyer, J., and Hueglin, C.: Design of an ozone and nitrogen dioxide sensor unit and its long-term operation within a sensor network in the city of Zurich, Atmos. Meas. Tech. Discuss., https://doi.org/10.5194/amt-2017-22, in review, 2017.

Sipilä, M., Berndt, T., Petäjä, T., Brus, D., Vanhanen, J., Stratmann, F., Patokoski, J., Mauldin, R. L., Hyvärinen, A.-P., and Lihavainen, H.: The role of sulfuric acid in atmospheric nucleation, Science, 327, 1243-1246, 2010.

Snyder, E. G., Watkins, T. H., Solomon, P. A., Thoma, E. D., Williams, R. W., Hagler, G. S. W., Shelow, D., Hindin, D. A., Kilaru, V. J., and Preuss, P. W.: The Changing Paradigm of Air Pollution Monitoring, Environ. Sci. Technol., 47, 11369-11377, 2013.
Stetter, J. R. and Li, J.: Amperometric Gas Sensors A Review, Chem. Rev., 108, 352-366, https://doi.org/10.1021/cr0681039, 2008.

WHO: Burden of disease from Ambient Air Pollution for 2012, World Health Organization, Geneva, available at: http://www.who.int/entity/phe/health_topics/outdoorair/ databases/AAP_BoD_results_March2014.pdf (last access: 27 April 2017), 2014.

Williams, R. K., Kaufman, A., Hanley, T., Rice, J., and Garvey, S.: Evaluation of Field-deployed Low Cost PM Sensors, U.S. EPA, Washington, DC, EPA/600/R-614/464, 2014a.

Williams, R. L., Long, R., Beaver, M., Kaufman, A., Zieger, F., Heimbinder, M., Acharya, B. R., Grimwald, B. A., Kupcho, K. A., and Robinson, S. E.: Sensor Evaluation Report U.S. EPA, Washington, DC, EPA/600/R-614/143, 2014b.

Zikova, N., Hopke, P. K., and Ferro, A. R.: Evaluation of new lowcost particle monitors for $\mathrm{PM}_{2.5}$ concentrations measurements, J. Aerosol Sci., 105, 24-34, 2017.

Zimmerman, N., Presto, A. A., Kumar, S. P. N., Gu, J., Hauryliuk, A., Robinson, E. S., Robinson, A. L., and Subramanian, R.: Closing the gap on lower cost air quality monitoring: machine learning calibration models to improve low-cost sensor performance, Atmos. Meas. Tech. Discuss., https://doi.org/10.5194/amt-2017260, in review, 2017. 